\title{
Working
}

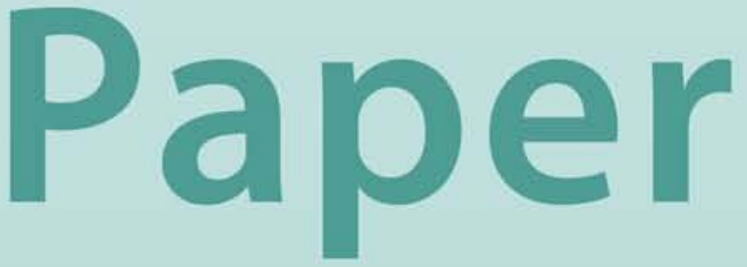




\section{Growth and Convergence in WAEMU Countries}

Abdoul Aziz Wane 


\title{
IMF Working Paper
}

\author{
African Department
}

\section{Growth and Convergence in WAEMU Countries}

\author{
Prepared by Abdoul Aziz Wane ${ }^{1}$ \\ Authorized for distribution by Cyrille Briançon and Edouard Maciejewski
}

October 2004

\begin{abstract}
This Working Paper should not be reported as representing the views of the IMF. The views expressed in this Working Paper are those of the author(s) and do not necessarily represent those of the IMF or IMF policy. Working Papers describe research in progress by the author(s) and are published to elicit comments and to further debate.

This paper investigates convergence and dynamic effects of human and physical capital on growth, in WAEMU countries. Using recently developed models for panel data and a growth accounting model, the study finds that growth is largely explained by changes in literacy rates and factor accumulation, but not by growth of total factor productivity (TFP).

Nevertheless, the panel estimation identifies aid, government spending, credit to the private sector, and openness as positive determinants of TFP growth, and government deficits as a negative determinant. The study also finds that per capita income in lower-income WAEMU countries converge to per capita income in higher-income ones when economic policies are similar. These results suggest opportunities for policymakers to enhance growth and convergence.
\end{abstract}

JEL Classification Numbers: D82, F35, I30, O23, O40

Keywords: Growth, Convergence, TFP growth, WAEMU, PMGE, Fixed effects

Author(s) E-Mail Address: awane@imf.org

\footnotetext{
${ }^{1}$ I would like to thank Cyrille Briançon, Oya Celasun, Ousmane Doré, Naheed Kirmani, Maitland MacFarlan, Jean-Claude Nachega, Arvind Subramanian, and Charalambos G. Tsangarides (IMF); and Jan Walliser (World Bank) for their helpful comments. Daneshwar Ghura (IMF) directed attention to the topic of the paper. Errors and omissions remain the author's responsibility.
} 
I. Introduction $\underline{4}$

II. Theoretical Background and Empirical Methodology ............................................... $\underline{5}$

A. Conceptual Framework for Growth Dynamics and Convergence in the WAEMU ........ $\underline{5}$

B. Alternative Empirical Models for Estimating Growth and Convergence Speed ............. $\underline{8}$

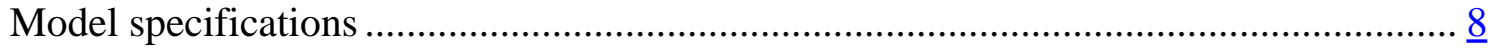

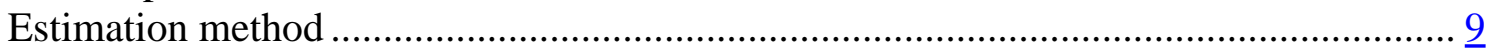

III. Empirical Results ..................................................................................... 10

A. Statistical Properties of the Variables .................................................................. 10

B. The Basic Solow Model and Its Augmented Version .............................................. $\frac{11}{15}$

C. What Drives TFP and TFP Growth in WAEMU? .............................................. 15

IV. Conclusions and Policy Implications............................................................ 22

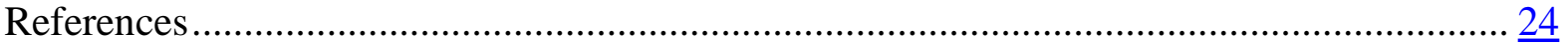

Appendices

I. Main Elements of a Neoclassical Type Growth Model ...........................................26

II. Estimation Issues, and Inconsistency Due to Ignored Heterogeneity ...........................28

III. Testing the Presence of Unit Root in Panel Data.................................................... $\frac{30}{32}$

IV. Sensibility of Results to Econometric Methodology .................................................

Tables

Table 1. $\beta$-Convergence of Per Capita GDP Growth Across WAEMU Countries ............... 10

Table 2. Estimation of Alternative Growth Models for WAEMU Countries Under the

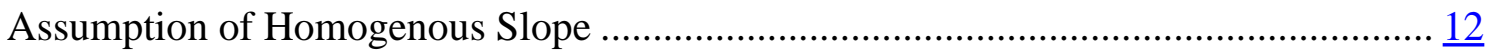

Table 3. PMG Estimates and MG Estimates for WAEMU Countries................................ 13

Table 4. Correlation of Selected Variables with Speed of Adjustment of WAEMU Countries

Table 5. Historical TFP Growth in WAEMU Countries, 1970-2000 .................................. $\frac{16}{16}$

Table 6. PMG and MG Estimates for TFP Growth in WAEMU Countries .......................... 19

Table 7. Simulations of TFP Improvements Needed for a 3 percent Growth of GDP per

Capita and Prioritization of Policy Variables .......................................................... 21

Appendix Tables

Table A3.1. Panel Unit Root Tests for Solow Growth Variables ........................................ 31

Table A4.1. Static Fixed Effects Estimates of the Augmented Solow Model....................... $\underline{32}$

Table A4.2. Dynamic Fixed Effects Estimates of the Augmented Solow Model ................. $\underline{32}$

Table A4.3. Summary of Results of OLS and PMLE Versions of the Long-run Coefficients

Based on ARDL Specifications with Pre-Specified Lags......................................... $\underline{33}$ 


\section{Figures}

Figure 1. Volatility of WAEMU Countries' Per Capita Output, 1965-2002 _......................... $\underline{6}$

Figure 2. GDP Per Capita of Individual WAEMU Countries ...........................................

Figure 3. International Price of Selected Commodities Produced in WAEMU Countries....... 1

Figure 4. TFP Growth for the WAEMU Zone and for WAEMU Countries, 1970-2000.......17

Figure 5. Relationship Between TFP Growth and Per Capita Output Growth......................18 


\section{INTRODUCTION}

The recent stream of papers arguing that growth is essential for poverty reduction ${ }^{2}$ has renewed the debate on the sources of economic growth in low-income countries. This debate is of particular importance for countries implementing poverty-reduction policies, because these policies emphasize the importance of growth. Member countries of the West African Economic and Monetary Union (WAEMU) ${ }^{3}$ have adopted the Millennium Development Goals (MDGs), and have prepared Poverty Reduction Strategy Papers (PRSPs) with ambitious growth objectives. However, these documents present little evidence regarding the sources of growth, casting doubt not only on the achievability of such growth objectives, but also on the suitability of the economic policies chosen to reach the growth targets.

WAEMU countries adopted in 1999 a regional "Pact of Convergence, Stability, Growth, and Solidarity" to strengthen economic stability and increase growth through regional integration. The Pact stresses the need to reinforce convergence of performance and macroeconomic policies through further progress in structural reforms and the harmonization of sectoral policies. The Pact is expected to spur growth by increasing economic discipline and reinforcing confidence in the currency, which is pegged to the euro. It calls for countries to observe a set of common accounting methods and judiciary standards. In 2000, a customs union was created within which tariffs barriers were lifted and a common external tariff established. Also, convergence criteria were set regarding budgetary and other macroeconomic policies.

This paper analyzes the dynamics of growth and convergence in WAEMU countries using a Solow-Swan-type model. Dynamic panel data methods are used to assess the convergence hypotheses in the zone. Following the estimation of the responses of economic activity to changes in factor inputs, a growth accounting framework is used to estimate the role of total factor productivity (TFP) gains in the growth performance of WAEMU countries.

Determinants of TFP growth are identified and a simulation exercise is conducted to assess the extent of TFP growth that would be needed for countries to meet the MDGs. The paper uses recently developed empirical models to produce consistent and efficient estimators of the parameters in the presence of country heterogeneity.

The paper is structured as follows: Section II presents the competing theoretical growth models and the econometric tools available for their estimation. Section III discusses the empirical results and investigates the determinants of TFP growth and its importance in explaining per capita growth in the WAEMU. The paper then discusses the growth in TFP required for per capita GDP to grow by 3 percent a year, deemed the minimum to reduce poverty by one half over the next ten years. The conclusion summarizes the findings, and suggests areas for further research.

${ }^{2}$ See David Dollar and Aart Kraay (2002) for instance.

${ }^{3}$ WAEMU comprises the following eight countries: Benin, Burkina Faso, Côte d'Ivoire, Guinea-Bissau, Mali, Niger, Senegal, and Togo. 


\section{Theoretical BACKground AND EMPIRICAL Methodology}

The neoclassical paradigm provides the theoretical underpinnings of modern growth theory. The main assumption of the neoclassical model is the law of diminishing returns to labor and reproducible capital. This hypothesis has two implications. First, factor accumulation should explain only short-term fluctuations of economic growth around its steady-state rate. Second, for a given saving rate, poor countries are likely to grow faster than richer ones, fostering convergence of per capita incomes among countries in the long run. In this setting, the differences in long-term growth of wealth per capita across countries cannot be explained by the growth rate of savings, but rather by technological progress. Nonetheless, the results of the empirical literature devoted to testing whether the data validate the theory have been at best mixed. In particular the neoclassical growth variables (rates of growth of physical capital, human capital, and the labor force) explain only a small share of the variations in per capita growth. Furthermore, as pointed out by Barro (1991), cross-country evidence indicates that per capita growth rates have little correlation with the initial level of per capita income. The small share of the variance of per capita growth explained by the Solow regressors has pushed growth empiricists to investigate additional determinants of growth. Endogenous growth theories modify the neoclassical model by introducing constant returns to scale for output in effective units of labor. Romer (1986) assumes increasing returns to scale after introducing technological change. Such models are consistent with the observed absence of convergence in per capita income and can explain the persistent wealth differences between countries with the same rates of accumulation of capital and population growth.

\section{A. Conceptual Framework for Growth Dynamics and Convergence in the WAEMU}

Growth theories have developed an accounting framework that allows the computation of the relative importance of factor accumulation and TFP in explaining per capita growth. They also provide a framework to assess the convergence hypothesis implied by the Solow model. The basic Solow model and its augmented form predict that each economy converges to its steady-state level of output per head. The early results of the applied literature using this model can be embodied in Barro's (1991) findings that estimate the speed of convergence at 2-3 percent a year ${ }^{4}$. The existence of a steady-state equilibrium for per capita output relies critically on the assumption of diminishing returns to labor and reproducible capital. If this assumption does not hold, the steady-state level of output per head is undefined and differences between countries can persist indefinitely even if they share the same rates of capital accumulation and population growth. The relaxation of this constraint is the main innovation introduced by the endogenous growth theory (see Lucas, 1988), which allows for the absence of absolute and conditional convergence ${ }^{5}$.

\footnotetext{
${ }^{4}$ See Tsangarides (2001) for a survey of the main contributions supporting the convergence hypothesis.

${ }^{5}$ Note that the neoclassical Solow-Swan model can also accommodate absence of absolute convergence among countries that have different saving rates.
} 
Absolute convergence occurs when per capita incomes of countries converge to a common steady-state level in the long run regardless of the country's initial conditions. Conditional convergence occurs when per capita incomes of countries that have a similar structure converge to a common steady-state level in the long run regardless of the countries' initial conditions. A third concept, "club convergence", differs from conditional convergence in that it implies that the initial conditions of individual countries are the same. The concept of absolute convergence (referred to as $\beta$-convergence) differs from an alternative concept (known as $\sigma$-convergence) according to which the dispersion of real per capita output across a group of countries tends to fall over time. Figure 1 below investigates the $\sigma$-convergence assumption in WAEMU countries by presenting the path of the second moment of the distribution of per capita output.

Figure 1. Volatility of WAEMU Countries’ Per Capita Output, 1965-2002

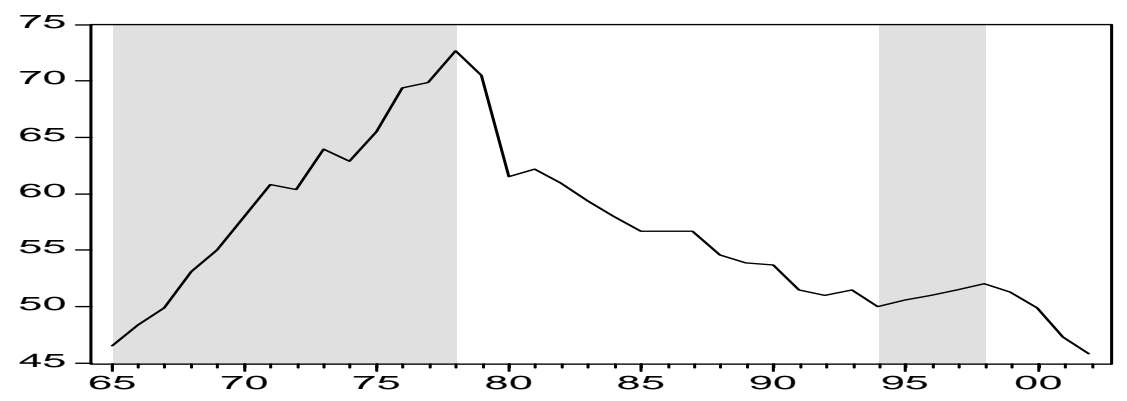

Source: BCEAO data and author's calculations

Figure 1 shows no clear indication of $\sigma$-convergence among WAEMU countries over the period 1965-2002 as a whole, although this is made up of periods of strong divergence (1965-78), and strong reduction in divergence (1979-2002). The dispersion of income, measured by the standard deviation of GDP per capita, was at about 46 percent of the average per capita income in 2002, as in 1965. The presence or absence of $\sigma$-convergence only indicates whether the wealth gap, or inequality of per capita income, among member countries has narrowed over time. Absence of $\sigma$-convergence does not tell anything about $\beta$ convergence or the existence of a steady-state level of per capita output.

Absolute convergence tends to be generated by $\sigma$-convergence. It can be shown that the dispersion of real GDP per capita decreases when the speed of absolute convergence increases. In this regard, the high and increasing dispersion of GDP per capita, especially before the 1980s, suggests a low speed of adjustment of WAEMU countries toward a common steady-state path and also a weak convergence of poor countries toward richer ones. Hence, the high dispersion of per capita GDP increases the likelihood that endogenous growth, based on increasing returns, might be at play and that neoclassical growth variables would not be sufficient to explain the bulk of the variations in growth. If a large part of the variation in per capita income can be explained by countries diverging from their steady-state paths, then conditional convergence can provide indications of the dispersion of income per capita across countries. Figure 2 shows that initial conditions in WAEMU countries were 
very different, with per capita income in Côte d'Ivoire (the richest country in the zone) 4.6 times larger than in Burkina Faso (the poorest one) at the beginning of the period.

Figure 2. GDP Per Capita of Individual WAEMU Countries ${ }^{1 /}$

(In U.S. dollars)

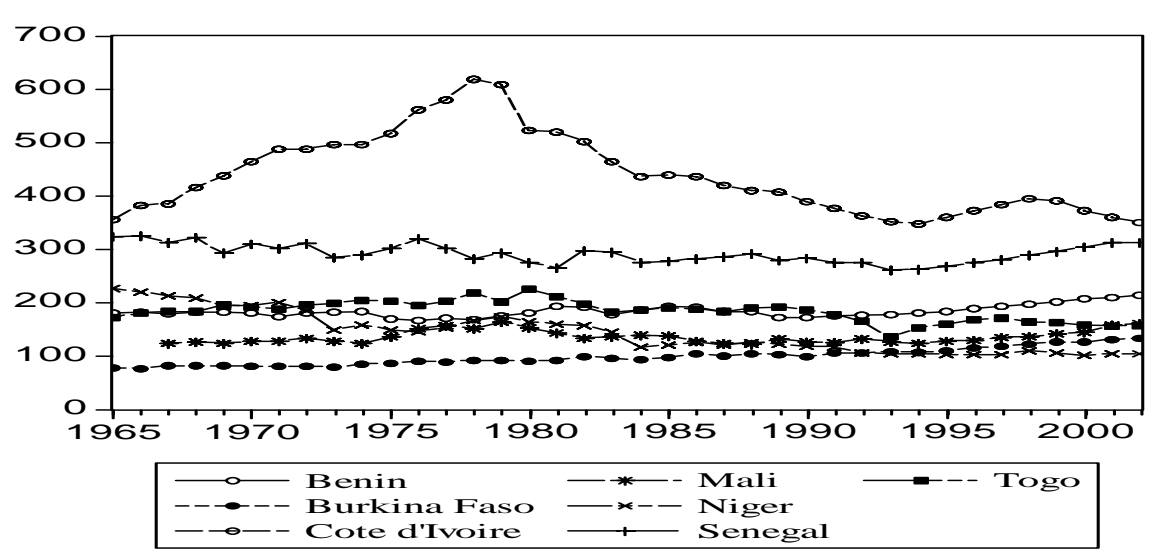

Source: BCEAO data and author's calculations

1/ The data exclude Guinea-Bissau, which joined the Union in 1998.

Even though Burkina Faso has made some progress in closing the income gap with the richer countries, there is no clear-cut evidence of the general "catch-up" prediction of the Solow model for the entire sample of countries, since the two richer ones at the beginning of the period are still in their initial relative position at the end of the period and the average dispersion has remained at about the same level. It is worth mentioning that the cross sectional dispersion of per capita output is sensitive to shocks that influence a subgroup of countries in the sample. In the case of the WAEMU zone, this dispersion is mainly driven by the sharp fluctuations in the international price of commodities (mainly those produced in Côte d'Ivoire, given its importance in the zone), which in turn affect the level of per capita income.

Figure 3. International Price of Selected Commodities Produced in WAEMU Countries
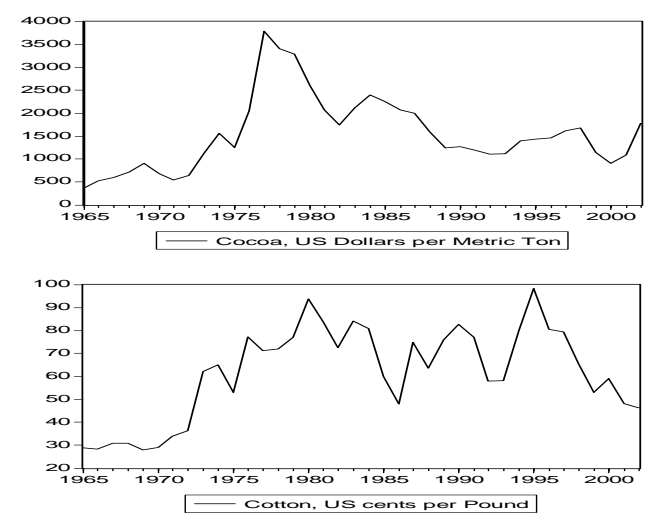

Source: World Economic Outlook, IMF
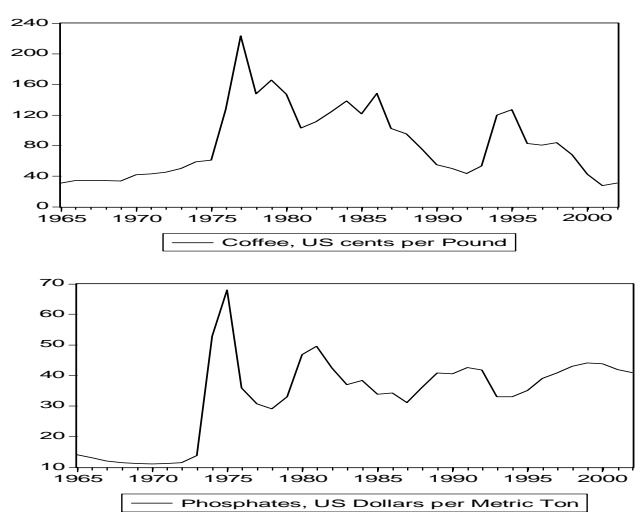
As shown in Figure 3, the price of cocoa produced in Côte d'Ivoire declined by an average 5 percent per year from its 1977 peak up to 1993, and has fluctuated significantly since then. The prices of coffee and phosphates are also substantially below their peak of the mid1970s, while cotton prices held up better until 1995, benefiting poorer countries such as Benin, Burkina Faso, and Mali, and reducing the divergence of per capita income.

The observed absence of $\sigma$-convergence also makes it likely that factor accumulation alone would not be sufficient to explain the differences in growth between countries in the WAEMU zone. Therefore, country specific variables - such as human capital accumulation, and other policy variables - and changes in total factor productivity might partially drive growth and account for its dispersion among countries (see Appendix I).

\section{B. Alternative Empirical Models for Estimating Growth and Convergence Speed}

In contrast with several studies on growth and convergence reported in the literature, a panel data approach is used, mainly because the number of countries in the WAEMU zone is too small for individual countries estimates to make use of statistical similarities across the region. Furthermore, since a larger number of observations is available, panel data have advantages over pure cross sections or pure time-series data, in that they make it possible to account for latent heterogeneity and to reduce the standard errors of point estimates (efficiency gains). Panel data also provide the possibility to specify and test more sophisticated dynamic models, as well as to alleviate multicollinearity problems.

\section{Model specifications}

Panel data models are used to investigate the type of convergence at play in the WAEMU countries, and to estimate the member countries' speed of convergence toward their steadystate level of per capita output. To discriminate between the different models of growth, the starting point will be a variation of a model used in Lee, Pesaran, and Smith (1997). We consider a regression of the first difference of log of per capita output on the lagged level of log of per capita output and an intercept, as well as a time trend.

$$
\Delta \ln y_{i t}=\text { cte }+ \text { trend }+\lambda \times \ln y_{i t-1}+\varepsilon_{i t}
$$

This specification will give insights into the issue of absolute convergence discussed above, since $\lambda$ can be interpreted as the speed of convergence toward a common steady state. Convergence toward different steady-state levels can be tested by relaxing the assumption of a common steady-state level and by comparing the predictive power of the constrained and the unconstrained models.

Conditional convergence is investigated by considering a dynamic equation with the lagged $\log$ of per capita output entering the list of regressors:

$\ln y_{i t}=a+g \times t+\varphi \times \ln y_{i t-1}+\frac{\alpha}{1-\alpha} \ln s_{i t}-\frac{\alpha}{1-\alpha} \ln \left(n_{i t}+g+\delta\right)+\varepsilon_{i t}$, where $g$ and $n$ represent the constant growth rate of technology and labor, respectively. $\delta$ and $s$ stand for the rate of 
depreciation of the capital stock, and the investment rate, respectively. ${ }^{6}$ By subtracting $\ln y_{i t-1}$ from both sides of the equation, it can be rewritten as:

$$
\Delta \ln y_{i t}=a+g \times t+\lambda \times \ln y_{i t-1}+\frac{\alpha}{1-\alpha} \ln s_{i t}-\frac{\alpha}{1-\alpha} \ln \left(n_{i t}+g+\delta\right)+\varepsilon_{i t}
$$

The assumptions of the basic Solow model can be tested in this setting and the speed of convergence $\lambda=\varphi-1$ can be estimated.

To address possible misspecification issues due to underparameterization we consider dynamic versions of the Human Capital Augmented (HCA) Solow model and its wider adaptation comprising policy variables. The role of human capital is assessed in this setting as well as the ability of the Solow model to capture the bulk of wealth accumulation in the WAEMU zone.

The derivation of the following model is explained in Appendix I.

$$
\begin{aligned}
\Delta \ln y_{i t} & =\gamma_{0}+g \times t+\lambda \times y_{i t-1}+\frac{\alpha}{1-\alpha-\beta} \ln s_{k i t}+\frac{\beta}{1-\alpha-\beta} \ln s_{h i t} \\
& -\frac{\alpha+\beta}{1-\alpha-\beta} \ln \left(n_{i t}+g+\delta\right)+\gamma^{\prime} \times X_{i t}+\eta_{i t}
\end{aligned}
$$

where $X$ stands for a list of policy variables; $s_{k}$ and $s_{h}$ represent the shares of output invested in physical and human ${ }^{7}$ capital respectively, and subscripts $i$, and $t$ a country and a time period, respectively. $\alpha$ and $\beta$ are the growth-elasticities of physical and human capital, respectively. Equations (1.3) represents the unconstrained model for growth dynamics. In order to determine the role of factor accumulation and technological change, equation (1.3) is estimated in two stages. First the Solow model is estimated and the residuals are retrieved; second, the residuals are regressed over policy variables thought to be key determinants of the efficiency in the use of factor inputs. The long run growth rates are thus simulated.

\section{Estimation method}

The first problem one is faced with when using panel data models is the choice of the estimation method, which is crucial to the validity of the estimates, since pooling the cross section and the time-series dimensions reduces the range of consistent and efficient estimation methods. Panel data are often estimated using fixed effects or random effects models. However, these methods can potentially produce inconsistent and/or inefficient estimates. We use in this paper the mean group and the pooled mean group estimates (see Appendix II).

${ }^{6}$ See Appendix I for a discussion of the neoclassical growth model.

${ }^{7}$ Literacy rates are used as a proxy for human capital, as they are deemed to be positively correlated with health status and education levels. 


\section{EMPIRICAL RESULTS}

This section presents the results of the estimation methods outlined above and carried out for the WAEMU countries. It starts by analyzing the statistical properties of the variables included in the traditional Solow model (growth, human and physical capital), as well as their implications for the estimation techniques (see Appendix III). It then estimates the basic and HCA Solow models, and further investigates the role of conditioning policy variables, and infers the unobservable impact of technology changes.

\section{A. Statistical Properties of the Variables}

Table A3.1 in the appendix presents the results for the unit root test conducted on the Solow growth variables. The results indicate that per capita output contains a unit root and is an I(1) process. However, the Solow regressors are I(0) processes. The existence of a unit root in the per capita output variable indicates that deviations of per capita output from its steady statelevel are permanent rather than transitory. This provides further evidence of absence of at most weak $\sigma$-convergence among WAEMU countries' income, which is reinforced by a simple autoregressive (AR(1)) model (see Table 1 below). The negative sign of the coefficient on the lagged dependent variable indicates that GDP per capita has converged toward its steady-state path for each country, and that in a long-term perspective, the wealth gap between richer and poorer countries in the zone has narrowed, albeit at a slow pace, during the period under analysis. The convergence speed is estimated at 6 percent on average over 1965-2002, which is consistent with Barro's finding (1991).

Table 1. $\beta$-Convergence of Per Capita GDP Growth Across WAEMU Countries

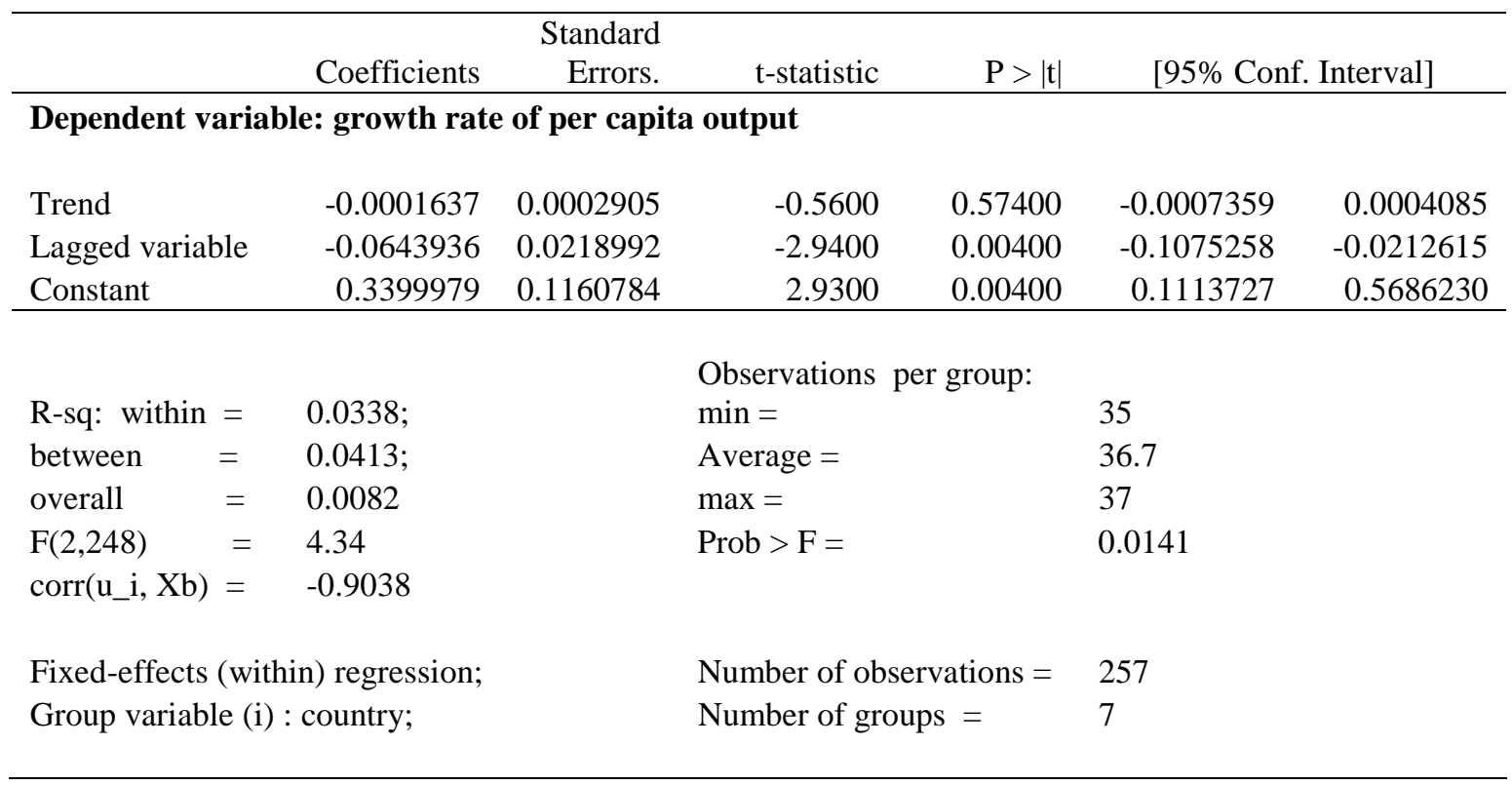

The convergence is absolute because it applies without controlling for explanatory variables other than the lagged per capita output. The low speed of convergence is consistent with the absence of $\sigma$-convergence. It would be interesting to investigate the stability of the 
convergence coefficient across time to look into the role of the convergence pact recently signed between these countries in accelerating adjustment capacity in the WAEMU zone. It should be noted that the estimate of the convergence speed might be biased if there are omitted variables. In this case, the estimation of growth dynamics and speed of convergence should be dealt with in a more appropriate framework. Such a framework is presented in the next sections.

\section{B. The Basic Solow Model and Its Augmented Version}

Table 2 presents results of the estimation of the growth equation. As mentioned above, the unconditional convergence hypothesis holds but the model for estimating the speed of convergence is weak and is likely to produce a downward bias in the point estimate of the speed of convergence. By improving the specification through a correction for omitted variables, the estimate of the speed of convergence increases, as well as the quality indicators of overall fitness of the model. The estimation of the Solow model, in its basic and human capital augmented versions, suggests a significantly higher speed of convergence of GDP per capita among WAEMU countries. Further, in line with the Solow model, the investment share in output is a strong determinant of GDP per capita growth in the WAEMU zone and an important policy variable that could support convergence in per capita output. However, the adjusted growth rate of labor force does not enter the regression with the expected sign. The estimation of the basic Solow model indicates that growth in per capita output in the zone is positively linked to the labor force growth, suggesting that these economies have a low level of capacity utilization and hence are much below their potential output (far from full employment). Any new worker has a productivity that is higher than the increase in physical capital needed to keep the ratio of investment to GDP at a level that can sustain growth of per capita output. However, it could also be the case that these results come from measurement errors of the labor force, given the scant census and surveys.

The results of the estimation reported in the last column of Table 2 indicate that the 1994 devaluation has changed the path of growth in WAEMU countries, lifting growth per capita by an average $3 \frac{1}{2}$ percent per year.

The constrained basic Solow model gives results that are in line with the theoretical prediction. In particular, human capital growth has only a weak impact on growth. This result is broadly in line with the findings of the relevant empirical literature (see for instance Pritchett, 2001; Sacerdoti and others, 1998). 
Table 2. Estimation of Alternative Growth Models for WAEMU Countries Under the Assumption of Homogenous Slope

\begin{tabular}{|c|c|c|c|c|c|c|}
\hline \multirow{3}{*}{ Variables } & \multirow{3}{*}{$\begin{array}{r}\begin{array}{c}\text { Unconditional } \\
\text { convergence }\end{array} \\
\mathrm{AR}(1)\end{array}$} & \multicolumn{5}{|c|}{ Conditional convergence } \\
\hline & & \multicolumn{2}{|c|}{ Basic Solow } & \multicolumn{3}{|c|}{ Augmented Solow } \\
\hline & & Unconstrained & Constrained & Unconstrained & Constrained & Devaluatior \\
\hline \multirow{2}{*}{$\begin{array}{l}\text { Constant } \\
(t \text {-statistic })\end{array}$} & 0.34 & 0.96 & 0.51 & 0.93 & 0.50 & 1.06 \\
\hline & 2.93 & 4.57 & 3.93 & 4.40 & 3.86 & 3.94 \\
\hline $\begin{array}{l}\text { Time trend } \\
(t \text {-statistic })\end{array}$ & -0.0002 & -0.0008 & -0.0005 & -0.0006 & -0.0002 & -0.002 \\
\hline (t-statistic) & -0.56 & -2.40 & -1.48 & -1.57 & -0.63 & -1.86 \\
\hline lagged variable & -0.06 & -0.11 & -0.10 & -0.11 & -0.10 & -0.11 \\
\hline (t-statistic) & -2.94 & -4.33 & -4.01 & -4.31 & -4.01 & -3.78 \\
\hline \multicolumn{2}{|c|}{ Investment share minus adjusted labor growth } & $\ldots$ & 0.02 & $\ldots$ & 0.03 & $\ldots$ \\
\hline$(t$-statistic $)$ & $\ldots$ & $\ldots$ & 0.01 & $\ldots$ & 3.00 & $\ldots$ \\
\hline \multirow{2}{*}{$\begin{array}{l}\text { Investment share } \\
(t \text {-statistic })\end{array}$} & $\ldots$ & 0.03 & $\ldots$ & 0.03 & $\ldots$ & 0.038 \\
\hline & $\ldots$ & 3.49 & $\ldots$ & 3.62 & $\ldots$ & 3.48 \\
\hline \multirow{2}{*}{$\begin{array}{l}\text { Adjusted labor force growth } \\
\text { (t-statistic) }\end{array}$} & $\ldots$ & 0.13 & $\ldots$ & 0.12 & $\ldots$ & 0.15 \\
\hline & $\ldots$ & 2.27 & $\ldots$ & 2.08 & $\ldots$ & 2.09 \\
\hline \multirow{2}{*}{$\begin{array}{l}\text { Human capital growth } \\
\text { (t-statistic) }\end{array}$} & $\ldots$ & & $\ldots$ & 0.000 & $1.91 \mathrm{E}-09$ & 0.05 \\
\hline & $\ldots$ & & $\ldots$ & 0.97 & 1.29 & 0.18 \\
\hline \multirow{2}{*}{$\begin{array}{l}\text { Devaluation dummy } \\
(t \text {-statistic })\end{array}$} & $\ldots$ & & & & & 0.036 \\
\hline & $\ldots$ & & & & & 3.11 \\
\hline F-statistic & 4.34 & 6.68 & 6.29 & 5.53 & 5.15 & 6.29 \\
\hline Prob $>F=$ & 0.0141 & 0.0000 & 0.0004 & 0.0001 & 0.0005 & 0.0000 \\
\hline
\end{tabular}

Nevertheless, the results may reflect the estimation technique that was used, which leads to estimates that are in general inconsistent, inefficient, and prone to bias. In particular, the technique fails to take into account the heterogeneity of countries in the sample and to distinguish between the long-run and the short-run effects. Intuitively, the return on investment in human capital cannot be detected in the growth series in the short term and one needs to build a model that contains both short-run and long-run parameters. Further, in the context of WAEMU countries, the model for estimating growth should test for correlation in country specific shocks. Monetary and price shocks are clearly positively correlated in these countries, as they are heavily dependent on the price of a similar group of commodities in the international markets, and have a common currency. The countries are also subject to the same weather shocks, which tend to have sizable impacts on their economies, given the importance of the agricultural sector.

Failure to take into account these features, and in particular, the ignored heterogeneity would give inconsistent estimates of the speed of convergence, which would tend toward zero even if the source of heterogeneity is purely random. This could explain partially the low speed of adjustment found by Barro and the ones presented in Tables 1-2 above.

We allow in the following for slope heterogeneity by considering the mean group estimation (MGE) of dynamic heterogeneous panels as first estimates to produce the pooled mean group estimates (PMGE) for which long-run slope homogeneity is assumed for the variables. 
The estimation of the HCA Solow model for WAEMU countries is conducted using an autoregressive model with distributed lags ( $A R D L(1,0,0,0)$; see Appendix IV). Table 3 below presents the results based on the PMGE. The estimation of the same equation under alternative and inferior methods is reported in Appendix IV, and the comparison of the results shows how sensitive the empirical estimates of the growth model are to different estimation techniques.

Table 3. PMG Estimates and MG Estimates for WAEMU Countries

\begin{tabular}{|c|c|c|c|c|c|c|c|c|}
\hline & \multicolumn{3}{|c|}{ Pooled MGE Estimates } & \multicolumn{3}{|c|}{ MGE Estimates } & \multicolumn{2}{|c|}{ Hausman test } \\
\hline & Coef. & St. Er. & t-ratio & Coef. & St. Er. & t-ratio & h-test & p-val \\
\hline \multicolumn{9}{|c|}{ Dependent variable: Log of GDP per capita } \\
\hline \multicolumn{9}{|l|}{ Long-run Coefficients } \\
\hline Log of investment share & 0.167 & 0.045 & 3.721 & 0.28 & 0.104 & 2.689 & 1.44 & 0.23 \\
\hline Log of labor force growth & 0.079 & 0.174 & 0.456 & 0.287 & 0.223 & 1.287 & 2.2 & 0.14 \\
\hline Log of human capital growth & 0.386 & 0.137 & 2.822 & 0.805 & 1.854 & 0.434 & 0.05 & 0.82 \\
\hline Joint Hausman test: & & 56.59 & 0.000 & & & & & \\
\hline \multicolumn{9}{|l|}{ Error Correction Coefficients } \\
\hline Phi & -0.266 & 0.094 & -2.838 & -0.429 & 0.102 & -4.219 & & \\
\hline \multicolumn{9}{|l|}{ Short-run Coefficients } \\
\hline Log of investment share & 0.045 & 0.016 & 2.838 & 0.065 & 0.023 & 2.797 & & \\
\hline Log of labor force growth & 0.021 & 0.007 & 2.838 & 0.1 & 0.078 & 1.285 & & \\
\hline Log of human capita growth & 0.103 & 0.036 & 2.838 & 0.36 & 0.596 & 0.604 & & \\
\hline Time trend & 0.001 & 0.0000 & 1.681 & 0.000 & 0.001 & 0.193 & & \\
\hline Intercept & -0.002 & 0.043 & -0.054 & 0.297 & 0.332 & 0.894 & & \\
\hline
\end{tabular}

* h-test is the Hausman test statistic with its associated p-value.

Comparing the results of the PMGE with other traditional estimators presented in the literature (some of which are produced in Appendix IV), it is clear that the documented absence of the link between per capita GDP and human capital stems from inadequacies with the estimation methods. In line with the theoretical predictions of the augmented Solow model, the PMGE shows a strong positive impact of human capital on per capita GDP in WAEMU countries, both in the long-run and in the shorter term. As one would expect, the long-run effect of human capital is of higher magnitude than the short term impact. The longterm human capital elasticity of per capita GDP is estimated at 0.4, while the investment elasticity of per capita GDP is 0.2. Labor force growth does not have a significant effect on per capita GDP, and further, as a major difference with previous estimates shown in Tables 1 and 2, the PMGE indicates a per capita GDP to investment elasticity that is higher than the elasticity to labor force growth. This indicates that the constrained model where the difference between investment share and adjusted labor force growth is used as a regressor 
would yield results that are consistent with the theory. The error correction coefficient, which represents the speed of adjustment in this specification, is negative and significant, confirming the view that per capita GDP in WAEMU countries converges to a common steady-state path.

The speed of adjustment is also higher than the one estimated with simple fixed effects models. The PMGE indicates an average speed of convergence of 27 percent, much higher than the 10-11 percent estimate with alternative simple methods presented in Table 2 above and in the literature. In summary, WAEMU countries converge to a common steady-state growth rate regardless of their specific economic policies with a speed of absolute adjustment of 6 percent. The speed of adjustment jumps to 27 percent once they harmonize their investment profile (conditional convergence). In this instance, the convergence criteria on investment increases the capacity of countries to absorb exogenous shocks. However, the average speed of adjustment obscures a large volatility in WAEMU countries' response to shocks. ${ }^{8}$ The individual speed of convergence ranges from a low of 2 percent for Burkina Faso to a high of 71 percent for Togo. Interestingly, the results show that landlocked countries like Burkina Faso, Mali, and Niger have lower speed of adjustment. Intuitively, and on top of geographical influences, one would expect the speed of convergence to be higher for countries that have a more flexible economic system. Hence, structural reforms aimed at promoting private investment should be viewed as policies that could increase the speed of adjustment. In addition, economic diversification offering opportunities to move from a productive activity that has experienced a negative price shock to an alternative source of income generation would help strengthen the countries' response to shocks.

Table 4 presents correlation coefficients between the speed of adjustment of each country and variables that could have an impact on the ability of a country to adjust to exogenous shocks. It shows that countries where the share of imports in GDP is high react more promptly to production shocks, and conversely those where the share of exports is high tend to react more slowly than others.

Table 4. Correlation of Selected Variables with Speed of Adjustment of WAEMU Countries

\begin{tabular}{lr}
\hline & $\begin{array}{c}\text { Correlation } \\
\text { coefficient }\end{array}$ \\
\hline Imports of goods and services (\% of GDP) & 0.6 \\
Manufacturing, value added (\% of GDP) & 0.3 \\
Manufacture imports (\% of merchandise imports) & 0.2 \\
Foreign direct investment, net inflows (\% of GDP) & 0.2 \\
Inflation, consumer prices (annual \%) & 0.05 \\
Exports of goods and services (\% of GDP) & -0.7 \\
Foreign direct investment, net inflows (\% of gross capital formation) & -0.5 \\
General government final consumption expenditure (\% of GDP) & -0.1 \\
Industry, value added (\% of GDP) & -0.1 \\
\hline
\end{tabular}

${ }^{8}$ See Table A4.3. 
In particular, countries that import relatively highly manufactured products also react more promptly to shocks. The negative correlation between exports and speed of convergence can be explained by the fact that WAEMU economies are not diversified and export raw commodities for which they are price takers. For example, an adverse shock in the price of cotton would reduce the production of cotton without increasing the production of another good to offset completely the loss of value added. An increased share of foreign direct investment (FDI) in GDP can also ease the transition of economies to their steady state. However, when FDI is combined with low levels of domestic contribution to national investment, it reduces the convergence speed. This could be interpreted as a call for more emphasis on encouraging domestic private sector-led growth. This is confirmed by the fact that lower government consumption appears to be an important policy tool for absorbing shocks and returning the economy to its steady-state growth path after an exogenous shock. The results show that the country's flexibility and responsiveness to shocks decreases when the government expenditure on final consumption increases.

It is worth mentioning that the share of the variance of per capita GDP that is captured by the Solow variables is low, indicating, in line with the literature on endogenous growth, that there are other forces that drive long term growth, in particular gains in factor productivity. Thus, the paper evaluates next the relative weight of factor utilization and factor productivity in explaining growth and differences in per capita GDP in the WAEMU zone.

\section{What Drives TFP and TFP Growth in WAEMU?}

For the purpose of growth accounting, TFP growth is equated in the literature to the residual of GDP growth that cannot be attributed to changes in the volume of factor inputs. The computation of average TFP growth for WAEMU countries has been obtained by retrieving the residuals from the regression that controls for the devaluation effect and that uses raw data that were not demeaned. The regression results are those presented in the last column of Table 2. This procedure would ensure that the common factor driving growth, if any, be accounted for in explaining variations of TFP growth. TFP growth for WAEMU is a nonweighted average of TFP for individual countries.

Table 5 indicates that total factor productivity growth has been very weak in explaining average growth of WAEMU economies over the last three decades and that per capita GDP growth was mainly driven by factor inputs. Indeed, the slow GDP per capita growth could be attributed partially to losses in the efficiency with which production factors are used, since the non-weighted average of TFP growth is negative at around -0.1 percent throughout the period 1970-2000, with substantial difference before and after 1994.

For some countries, the estimates for TFP growth are quite high compared with the results found in the literature on growth accounting. This could be explained by the scale of WAEMU economies, which are small and poor economies with a very low endowment of technology. Hence, for a given technological innovation, the smaller the initial endowment the higher the growth of TFP. It is also possible that TFP growth as reported in Table 5 encompasses disturbances due to phenomena such as institutional changes, or civil or armed unrest, which happened in several countries during the period under analysis. 
Table 5. Historical TFP Growth in WAEMU Countries, 1970-2000

\begin{tabular}{|c|c|c|c|c|c|c|c|c|}
\hline & Benin & Burkina & $\begin{array}{r}\text { Cote } \\
\text { d'Ivoire } \\
\end{array}$ & Mali & Niger & Senegal & Togo & WAEMU \\
\hline \multicolumn{9}{|l|}{ Mean } \\
\hline 1970-2000 & 0.7 & 5.7 & -8.8 & 3.7 & 2.5 & -5.4 & 0.6 & -0.1 \\
\hline $1970-1993$ & 0.6 & 5.5 & -9.5 & 3.4 & 1.6 & -6.0 & 0.0 & -0.6 \\
\hline 1994-2000 & 1.2 & 6.2 & -6.2 & 4.9 & 5.7 & -3.3 & 2.7 & 1.6 \\
\hline \multicolumn{9}{|l|}{ Median } \\
\hline 1970-2000 & 1.5 & 6.0 & -9.1 & 3.8 & 2.5 & -5.6 & 0.8 & 0.0 \\
\hline 1970-1993 & 0.7 & 5.9 & -10.1 & 2.6 & 1.9 & -6.1 & 0.3 & -0.7 \\
\hline 1994-2000 & 1.2 & 6.2 & -6.2 & 4.9 & 5.7 & -3.3 & 2.6 & 1.6 \\
\hline \multicolumn{9}{|l|}{ Maximum } \\
\hline $1970-2000$ & 3.3 & 7.7 & -4.1 & 9.5 & 6.5 & -2.5 & 3.4 & 2.4 \\
\hline 1970-1993 & 3.1 & 6.6 & -6.6 & 8.9 & 2.9 & -3.9 & 1.5 & 1.0 \\
\hline 1994-2000 & 2.1 & 7.2 & -4.0 & 6.1 & 5.7 & -2.4 & 2.8 & 2.5 \\
\hline \multicolumn{9}{|l|}{ Minimum } \\
\hline 1970-2000 & -3.2 & 3.0 & -12.2 & -0.1 & -2.0 & -8.3 & -3.9 & -2.2 \\
\hline $1970-1993$ & -1.8 & 3.3 & -10.8 & 1.4 & -1.5 & -7.6 & -2.5 & -2.1 \\
\hline 1994-2000 & 0.3 & 5.1 & -8.4 & 3.6 & 5.6 & -4.2 & 2.6 & 0.7 \\
\hline \multicolumn{9}{|l|}{ Std. Dev. } \\
\hline 1970-2000 & 2.1 & 1.2 & 2.1 & 2.4 & 2.4 & 1.6 & 1.8 & 1.3 \\
\hline $1970-1993$ & 2.0 & 1.0 & 1.3 & 2.2 & 1.2 & 1.1 & 1.0 & 1.0 \\
\hline $1994-2000$ & 0.7 & 0.8 & 1.6 & 0.9 & 0.1 & 0.6 & 0.1 & 0.7 \\
\hline \multicolumn{9}{|c|}{ Memorandum item } \\
\hline \multicolumn{9}{|c|}{ Growth of real GDP per capita } \\
\hline 1965-2002 & 0.5 & 1.5 & 0.1 & 0.9 & -1.9 & 0.0 & -0.1 & 0.1 \\
\hline $1965-1993$ & 0.0 & 1.3 & 0.1 & 0.2 & -2.5 & -0.7 & -0.7 & -0.4 \\
\hline 1994-2002 & 2.1 & 2.3 & 0.0 & 2.9 & 0.1 & 2.0 & 1.7 & 1.6 \\
\hline
\end{tabular}

Fluctuations over time in TFP growth for the zone as a whole have also been pronounced with 1994 appearing as a break point - between a minimum of -2.2 percent and a maximum of 2.5 percent. Similarly, fluctuations between countries are striking, with the richest countries recording the worst performance and the smallest and poorest economies benefiting from marked improvement in the efficiency of capital utilization. Indeed, the loss of productivity gains are solely due to the weak performances of Côte d'Ivoire and Senegal, which are the only countries that have negative TFP growth on average. For all other countries TFP has been growing, albeit at different paces across time and countries.

The panels in Figure 4 represent the long-term TFP growth obtained by filtering the residuals using the Hodrick-Prescott methodology to produce a smooth estimate of the long-term component of the residuals. The discontinuity of the pattern of TFP growth reflects the impact of the 1994 devaluation of the CFA franc, which has lifted up temporarily the competitiveness and productivity of the economies in the zone. 
Figure 4. TFP Growth for the WAEMU Zone and for WAEMU Countries, 1970-2000
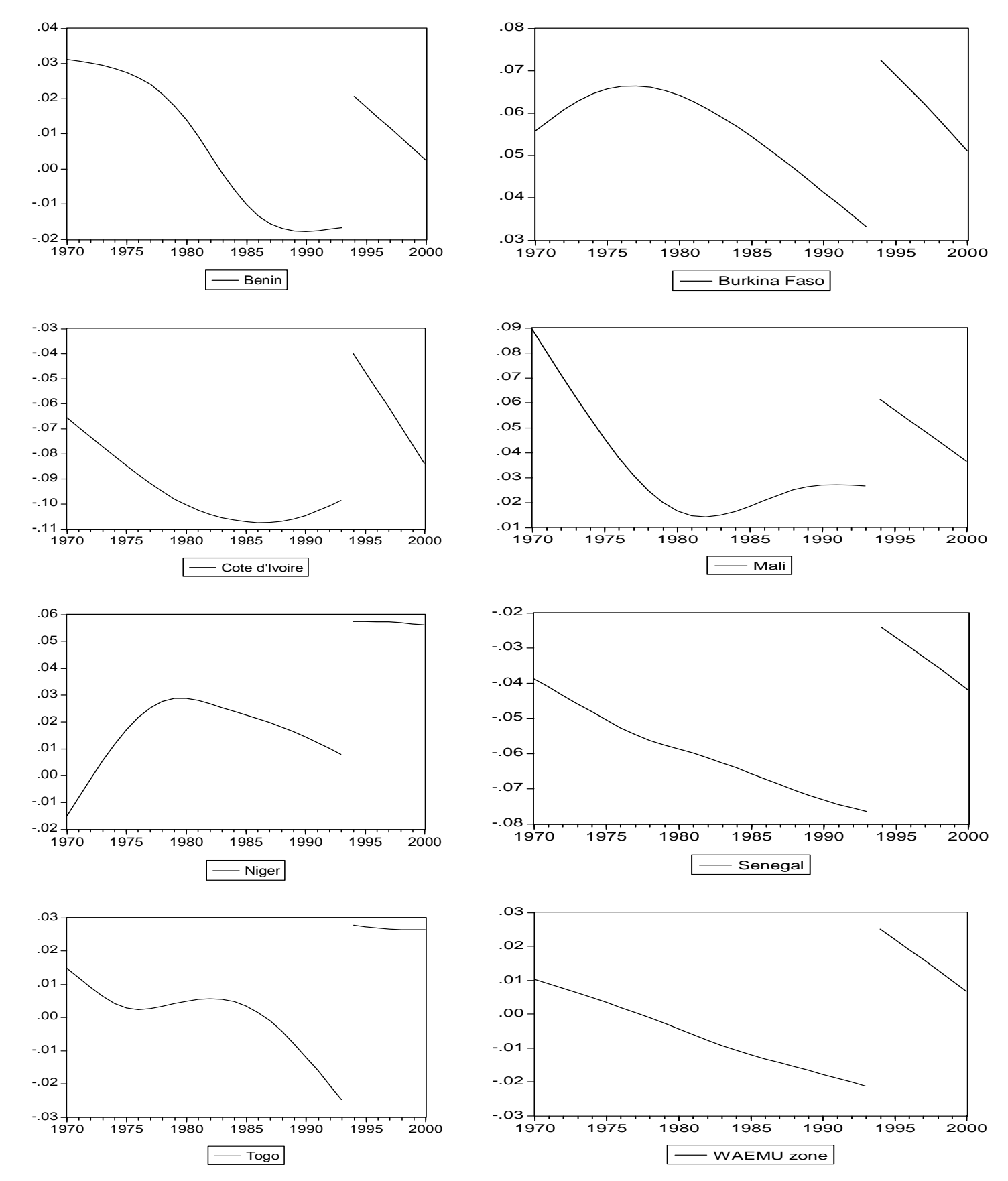
Factor accumulation during the period 1970-2000 explained the bulk of growth, especially before the CFA devaluation in January 1994. In this period, the Solow residuals were mostly negative for the WAEMU zone as a whole before jumping to positive values after the devaluation.

In the remainder of this section, we investigate the determinants of TFP growth. Drawing on previous research, these determinants are split into several categories that account for the sources of investment, the role of the financial sector along the lines developed by the theory of financial repression of McKinnon and Shaw (1971), the role of openness and international trade, and the importance of domestic stability and fiscal policy. Figure 5 displays a positive relationship between TFP growth and growth of per capita output. Hence, the determinants of TFP foster growth by improving the efficiency of the economies.

Figure 5. Relationship Between TFP Growth and Per Capita Output Growth

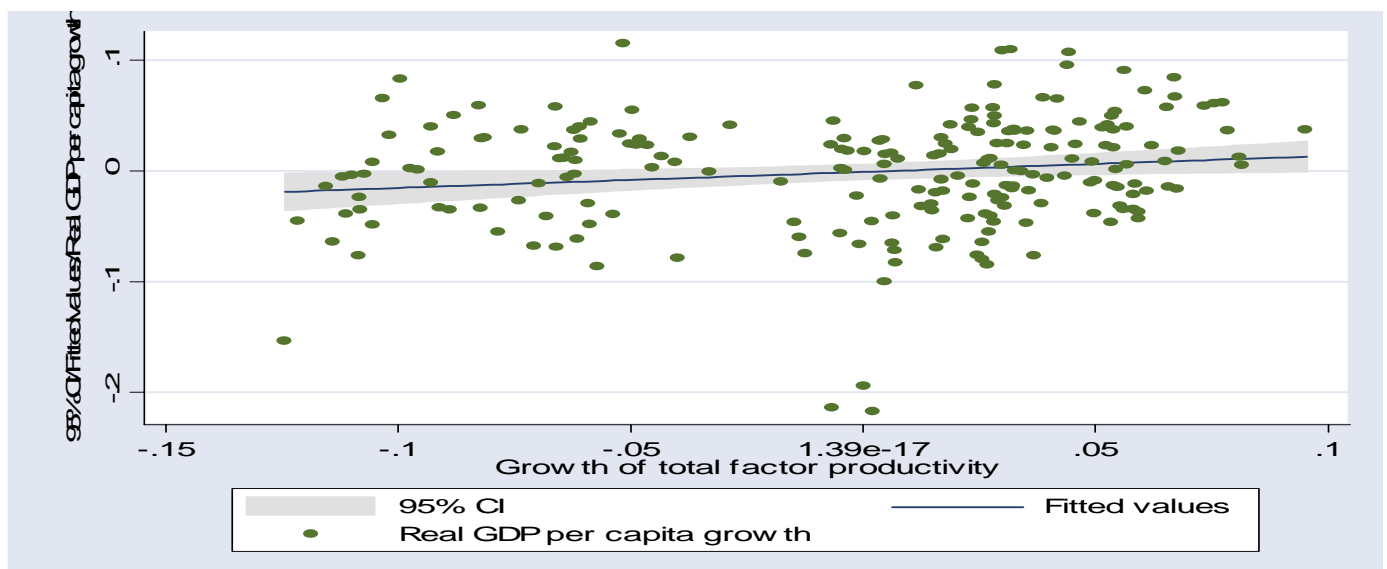

Table 6 below shows the determinants of TFP growth in WAEMU countries using macroeconomic data that are readily available and that economists generally regard as important policy variables for growth. Although it would be useful to include microeconomic data on factor cost, this was not done due to limitations on data quality and availability.

These results are satisfactory since the long-term impact of the policy variables is consistent with expectations built by the economic literature. First the error correction term is large and highly significant. This implies that countries with the highest level of TFP tend to record the lowest improvements in this variable. Côte d'Ivoire and Senegal had probably the highest level of factor productivity and had recorded the lowest levels of TFP growth, as shown by Figure 4. In both countries, the stock of physical capital was larger and the economies were more developed at independence. 
Table 6. PMG and MG Estimates for TFP Growth in WAEMU Countries

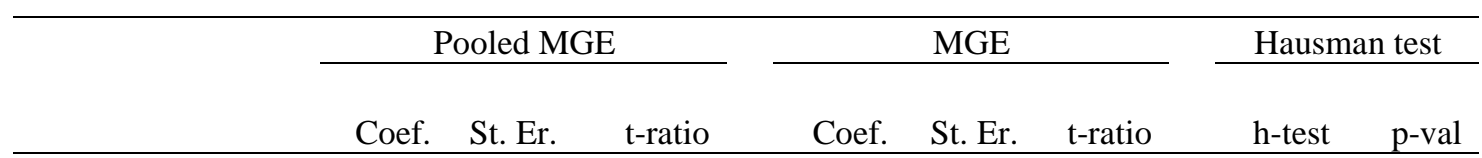

Dependent variable: Growth of Total Factor Productivity

$\begin{array}{lrrrrrrrr}\text { Long-run Coefficients } & & & & & & & \\ \text { Lycl } & -0.111 & 0.011 & -10.193 & -0.113 & 0.036 & -3.121 & 0.000 & 0.950 \\ \text { Cgte } & 0.099 & 0.029 & 3.412 & 0.164 & 0.083 & 1.965 & 0.690 & 0.410 \\ \text { Aid } & 0.036 & 0.007 & 5.453 & -0.062 & 0.047 & -1.308 & 4.330 & 0.040 \\ \text { pscr } & 0.095 & 0.025 & 3.754 & 0.017 & 0.185 & 0.090 & 0.180 & 0.670 \\ \text { Trd } & 0.055 & 0.016 & 3.421 & 0.009 & 0.051 & 0.182 & 0.890 & 0.350 \\ \text { Inf } & -0.017 & 0.016 & -1.053 & -0.042 & 0.022 & -1.890 & 2.740 & 0.100 \\ \text { Cgb } & 0.074 & 0.027 & 2.704 & 0.209 & 0.238 & 0.876 & 0.330 & 0.570\end{array}$

Error Correction Coefficients

$\begin{array}{lllllll}\text { Phi } & -0.566 & 0.156 & -3.62 & -0.83 & 0.145 & -5.704\end{array}$

Short-run Coefficients

\begin{tabular}{|c|c|c|c|c|c|c|}
\hline lycl & -0.063 & 0.017 & -3.620 & -0.088 & 0.026 & -3.351 \\
\hline cgte & 0.056 & 0.015 & 3.620 & 0.102 & 0.043 & 2.356 \\
\hline aid & 0.020 & 0.006 & 3.620 & -0.024 & 0.022 & -1.076 \\
\hline pscr & 0.054 & 0.015 & 3.620 & -0.056 & 0.119 & -0.469 \\
\hline $\operatorname{trd}$ & 0.031 & 0.009 & 3.620 & 0.023 & 0.028 & 0.822 \\
\hline inf & -0.010 & 0.003 & -3.620 & -0.029 & 0.020 & -1.488 \\
\hline cgb & 0.042 & 0.012 & 3.620 & 0.103 & 0.107 & 0.961 \\
\hline$\Delta \mathrm{lycl}$ & -0.028 & 0.018 & -1.540 & 0.000 & 0.022 & -0.009 \\
\hline$\Delta$ cgte & -0.014 & 0.014 & -0.948 & -0.050 & 0.041 & -1.233 \\
\hline$\Delta$ aid & -0.004 & 0.005 & -0.839 & 0.020 & 0.016 & 1.303 \\
\hline$\Delta$ pscr & -0.009 & 0.025 & -0.354 & 0.010 & 0.054 & 0.186 \\
\hline$\Delta \operatorname{trd}$ & -0.020 & 0.017 & -1.183 & -0.017 & 0.020 & -0.852 \\
\hline$\Delta \inf$ & -0.002 & 0.002 & -1.000 & 0.007 & 0.007 & 1.000 \\
\hline$\Delta c g b$ & -0.015 & 0.020 & -0.779 & -0.063 & 0.065 & -0.958 \\
\hline Intercept & -0.003 & 0.004 & -0.769 & -0.025 & 0.008 & -2.998 \\
\hline \multicolumn{7}{|c|}{$\begin{array}{l}\text { lycl = lagged value of log of per capita output } \\
\text { cgte = central government total expenditures and net lending in percent of GDP } \\
\text { aid = aid per capita in U.S. dollars } \\
\text { pscr = bank credit to the private sector in percent of GDP } \\
\text { trd = trade as a percentage of GDP }(\mathrm{X}+\mathrm{M} / \mathrm{Y})=\text { indicator of trade openness } \\
\text { inf = inflation measured as percentage change of annual consumer price index (CPI) } \\
\text { cgb = central government fiscal balance (including grants) in percent of GDP } \\
\text { The sign } \Delta \text { before a variable means the first difference of the variable. }\end{array}$} \\
\hline
\end{tabular}


The magnitude of the error correction coefficient is more than twice the estimated convergence speed in per capita output growth and is statistically more robust. Hence, the bulk of economic convergence seems to have been driven by convergence in TFP. Small economies in the zone were able to catch up with larger ones through a better utilization of factors rather than a more intense use of inputs.

Government expenditure is found to have a positive impact on TFP growth. This may reflect for example the fact that public investment can enhance the profitability of private investments. Such expenditure should of course be accompanied with fiscal soundness. Indeed, gains in TFP are higher when the government runs limited fiscal deficits.

The positive sign on private sector credit emphasizes the importance of a healthy financial system that can extend credit to private enterprises at affordable costs. It is also an indication that private investment is a major determinant of TFP growth since private investment and credit to the private sector are positively linked.

Openness and aid from multilateral and bilateral donors also positively affect TFP and appear to be important channels through which sustainable growth can be effective. The results obtained for WAEMU countries provide a clear answer to the question raised by the literature on aid. Aid improves growth in WAEMU countries, and the channels are found to go beyond the mechanical increase in investment. Aid improves the average efficiency of factor inputs as it is usually combined with conditionality and procedures to ensure its sound utilization. Aid is also often accompanied with policy advice and technology transfers that help improve factor productivity. In line with the theory of poverty traps, sufficiently high levels of foreign aid would be expected to put WAEMU economies on a path that leads to high steady-state growth.

Table 7 below presents the sources of growth for WAEMU countries. It also simulates the improvements in TFP that would be needed for each country to reach a targeted growth of real GDP per capita of 3.0 percent, which could be viewed as the minimum growth rate to reduce poverty.

If factor accumulation is to remain at its average historical level, a 3.2 percent increase in TFP growth from its current level should be recorded for the WAEMU to reach the targeted growth rate of GDP per capita. None of the WAEMU countries has a combination of TFP growth and factor accumulation to reach the targeted growth rate in GDP per capita. Hence, meeting the MDGs would need intense efforts to improve TFP as well as to strengthen the stock of capital, human and physical. Countries that need to significantly boost the efficiency in their use of inputs are, in decreasing order, Niger, Togo, Côte d'Ivoire, and Senegal. Burkina Faso, Mali, and Benin are in contrast the countries that are closest to their requisite TFP growth to reach the assumed growth of per capita output. 
Table 7. Simulations of TFP Improvements Needed for a 3 percent Growth of GDP per Capita and Prioritization of Policy Variables

\begin{tabular}{|c|c|c|c|c|c|c|c|c|}
\hline & & Burkina & Cote & & & & & \\
\hline & Benin & Faso & d'Ivoire & Mali & Niger & Senegal & Togo & WAEMU \\
\hline \multicolumn{9}{|l|}{ Historical } \\
\hline Growth of real GDP per capita & 0.5 & 1.4 & -0.4 & 0.6 & -1.8 & 0.2 & -0.5 & -0.2 \\
\hline Factor accumulation & -0.3 & -4.2 & 8.4 & -3.1 & -4.4 & 5.6 & -1.1 & 0.0 \\
\hline Total factor productivity & 0.7 & 5.7 & -8.8 & 3.7 & 2.5 & -5.4 & 0.6 & -0.1 \\
\hline \multicolumn{9}{|l|}{ Medium term projections } \\
\hline Real GDP growth & 3.0 & 3.0 & 3.0 & 3.0 & 3.0 & 3.0 & 3.0 & 3.0 \\
\hline Factor accumulation & -0.3 & -4.2 & 8.4 & -3.1 & -4.4 & 5.6 & -1.1 & 0.0 \\
\hline Increase in TFP growth & 2.5 & 1.6 & 3.4 & 2.4 & 4.8 & 2.8 & 3.5 & 3.2 \\
\hline \multicolumn{9}{|l|}{ Determinants of TFP growth } \\
\hline Consumer price index & $\ldots$ & $\ldots$ & $\ldots$ & $\ldots$ & ... & $\ldots$ & $\ldots$ & $\ldots$ \\
\hline Total expenditure & 2 & 6 & 5 & 7 & 1 & 4 & 3 & $\ldots$ \\
\hline Credit to private sector & 2 & 3 & 5 & 4 & 1 & 6 & 7 & $\ldots$ \\
\hline Trade (\% of GDP) & 3 & 1 & 6 & 4 & 2 & 5 & 7 & $\ldots$ \\
\hline Aid per capita & 5 & 3 & 6 & 4 & 2 & 7 & 1 & $\ldots$ \\
\hline Central government balance & 6 & 4 & 5 & 2 & 3 & 7 & 1 & $\ldots$ \\
\hline Average relative country priority & 3.6 & 3.4 & 5.4 & 4.2 & 1.8 & 5.8 & 3.8 & $\ldots$ \\
\hline \multicolumn{9}{|l|}{ Memorandum item } \\
\hline Average GDP per capita (in US dollars) & 182.1 & 98.0 & 436.9 & 132.6 & 124.4 & 284.8 & 187.8 & 207.5 \\
\hline
\end{tabular}

The bottom of the table presents the policy variables that were found significant in the explanation of TFP growth. The numbers in the table are ranks attributed to the countries relative to each variable. A number $j$ found at the intersection of a country and a variable means that the country occupies the $j^{\text {th }}$ worst performance among WAEMU countries relative to this variable. Hence, the lower the rank, the higher the priority that the country should devote to this variable to foster TFP growth. The last row of the table ranks the countries by averaging the ranks attributed to each variable. Here also, the lower the rank, the higher the need for sound macroeconomic policies to foster TFP growth.

Niger appears to be the country that needs the most improvement in macroeconomic policies to foster TFP growth. In particular, increasing the government's capacity to spend in targeted sectors and strengthening the financial sector would support growth at a given level of factor accumulation through gains in TFP growth. Although Burkina Faso has recorded the highest TFP growth in the zone, it ranks second, behind Niger, for countries in which further improvement in macroeconomic policies would be welcome. In particular, further opening this landlocked country to international trade, as well as increasing the banking sector's participation in the financing of private companies would foster TFP growth. The case of Benin is interesting as it shows a country needing an improvement in almost all listed macroeconomic variables, but with relatively low intensity. TFP growth would be fostered in the case of Togo by increasing international assistance to that country and strengthening its fiscal stance. The economy of Mali would also gain from a tightening of the government 
fiscal balance along with the improvement in the allocation of public resources ${ }^{9}$. As regards Côte d'Ivoire and Senegal, which had the lowest TFP growth in the WAEMU zone, it appears that the priority for improving TFP growth does not lie in further macroeconomic adjustment, but rather in the implementation of structural measures that would reduce distortions and the role of the government.

\section{Conclusions And Policy Implications}

This paper has investigated the convergence assumptions of the Solow model and the determinants of growth in WAEMU countries. The econometric methodologies used have consistently accepted the absolute convergence as well as the conditional convergence hypotheses. When the countries' specific variables are not controlled for, WAEMU economies tend to converge to a steady-state growth rate of real per capita GDP with a speed of 6 percent a year. Countries with similar investment ratios converge at least three to four times faster to their common steady-state value. The speed of convergence has also been found to be correlated with proxies of the economies' openness and indicators of flexibility.

Using econometric techniques that allow a distinction between short-term and long-term effects, the paper has found that investment in human capital is an important determinant of per capita output growth.

The growth accounting exercise has shown that growth has been mainly driven by factor accumulation rather than TFP growth in WAEMU countries and that the weak growth performances observed took place because of deteriorating efficiency in the use of productive capital, mainly in the two larger economies. Given the quality constraints of macroeconomic data, it would be interesting in further research to conduct a growth accounting exercise using the dual TFP methodology to assess the robustness of the results presented in this paper that uses the primal growth accounting method. ${ }^{10}$

The paper also found that TFP is correlated with exogenous macroeconomic data, suggesting the existence of increasing returns to scale and imperfect competition. These results indicate

\footnotetext{
${ }^{9}$ The results show that increased government spending improves TFP. However, they indicate that this should be done in the context of an improved fiscal stance. It is also likely that there exists a threshold level from where the impact of government spending on TFP could become less positive or even negative. Hence, improving the quality of spending instead of its quantity is better advice, especially for countries with relatively high levels of government spending.

${ }^{10}$ The dual TFP methodology focuses on the price-cost side of the production theory and applies the cost function as the dual equivalent of the production function. If the share of labor and capital in GDP are constant, the growth rate of primal TFP equals the growth rate of dual TFP. The dual TFP methodology provides a means of checking data consistency: in East Asia, for example, the dual approach suggests much lower TFP growth than the primal approach, generating a heated debate on the actual sources of growth.
} 
that TFP can be improved by the implementation of sound macroeconomic policies that would significantly enhance the government's fiscal position. TFP would also, in all probability, be strengthened by a better allocation of savings through a stronger financial sector. For countries like Côte d'Ivoire and Senegal, the results suggest that the marginal effect on growth of further macroeconomic adjustment would be less important than in other countries in the zone, and that, relative to other countries in the zone, the emphasis should be placed on structural reforms and/or political stability. The results also indicate that government spending is not a deterrent to growth, when combined with a sound fiscal stance. Sound macroeconomic and structural policies along with aid from the international community are much needed in order for the countries to reach the Millennium Development Goals set in their poverty reduction strategies. It would also be interesting to investigate whether, at the level of development of WAEMU countries, aid has diminishing returns. This would be a valuable input for development agencies to design ex ante the path of their assistance to WAEMU countries. 


\section{REFERENCES}

\section{Fixed and Random Effects Models of Panel Data}

Hausman, J. A. and W. E. Taylor, 1981, "Panel Data and Unobservable Individual Effects," Econometrica, Vol. 49, pp. 1377-98.

\section{Dynamic Panel Data with Homogenous Slopes}

Ahn, S. C. and P. Schmidt, 1995, "Efficient Estimation of Models for Dynamic Panel Data," Journal of Econometrics, Vol. 68, pp. 5-27.

Arellano, M. and S. Bond, 1991, "Some Tests of Specification for Panel Data: Monte Carlo Evidence and an Application to Employment Equations", Review of Economic Studies, Vol. 58, pp. 277-297.

Binder, M., C. Hsiao, and M. H. Pesaran, 2002, "Estimation and Inference in Short Panel Vector Autoregressions with Unit Root and Cointegration" (unpublished: University of Maryland, University of South California, and Cambridge University.).

Hsiao, C., M. H. Pesaran, and A. K. Tahmiscioglu, 2002, "Maximum Likelihood Estimation of Fixed Effects Dynamic Panel Data Models Covering Short Time Periods," Journal of Econometrics, Vol. 109, pp. 107-50.

\section{Dynamic Panel Data with Heterogeneous Slopes}

Pesaran, M. H., Y. Shin, and R. P. Smith, 1998, "Pooled Mean Group Estimation of Dynamic Heterogeneous Panels," Journal of the American Statistical Association, Vol. 94, pp. 621-34.

Pesaran, M. H., and R. P. Smith, 1995, "Estimating Long-Run Relationships from Dynamic Heterogeneous Panels," Journal of Econometrics, Vol. 68, pp. 79-113.

Pesaran, M. H., and Z. Zhao, 1999, "Bias Reduction in Estimating Long-Run Relationships from Dynamic Heterogeneous Panels", in C. Hsiao, K. Lahiri, L.-F. Lee, and M.H. Pesaran (eds.), Analysis of Panels and Limited Dependent Variables: A Volume in honor of G. S. Maddala, Cambridge University Press, pp. 297-321.

\section{Testing for Unit Roots and Cointegration in Panels}

Chang, Y., 2002, "Nonlinear IV Unit Root Tests in Panels with Cross-sectional Dependency," Journal of Econometrics, Vol. 110, pp. 261-92.

Im, K. S., M. H. Pesaran, and Y. Shin, 2002, “Testing for Unit Root in Heterogeneous Panels", Journal of Econometrics. 


\section{Multi-Country Analysis of Growth, Convergence, Consumption and Saving}

Barro, R., 1991, "Economic Growth in a Cross Section of Countries", Quarterly Journal of Economics, Vol. 106, pp. 407-443.

Brock, W. A. and S. N. Durlauf, 2001, "Growth Empirics and Reality," World Bank Economic Review, Vol. 15, pp. 229-72.

Favero, C. A., 2001, Applied Macroeconometrics, Oxford University Press.

Haque, N. U., M. H. Pesaran, and S. Sharma, 2000, "Neglected Heterogeneity and Dynamics in Cross-Country Savings Regression," in Panel Data Econometrics - Future Directions, ed. By J. Krishnakumar and E. Ronchetti in Honor of Professor Balestra, Elsevier Science, pp. 53-82.

Lee, K., M. H. Pesaran, and R. P. Smith, 1997, "Growth and Convergence in a MultiCountry Empirical Stochastic Solow Model”, Journal of Applied Econometrics, Vol. 12, pp. 357-392.

_ 1998 , "Growth Empirics: a Panel Data Approach - A Comment”, Quarterly Journal of Economics, Vol. 113, pp. 319-323.

Masson, P. R., T. Bayoumi, and H. Samiei, 1998, "International Evidence on the Determinants of Private Savings"," World Bank Economic Review, Vol. 12, pp. 483-501.

Mankiw, N.G., D. Romer, and D.N. Weil, 1992, A Contribution to the Empirics of Economic Growth", Quarterly Journal of Economics, Vol. 107, pp. 407-437.

Tsangarides, C. G., 2001, "On cross-country growth and convergence: evidence from African and OECD countries", Journal of African Economies (u.k.); 10, no. 4, pp. 355-89.

\section{Determinants of Growth}

Dollar, D. and A. Kraay, 2002, "Growth is good for the poor", Journal of Economic Growth, Vol. 7 Issue n3, pp. 195-225

Hansen, H., F. Tarp, 2001, “Aid and Growth Regressions”, Journal of Development Economics, Vol. 64, pp. 547-570.

Pritchett, L., 2001, "Where has all the education gone?" , World Bank Economic Review; 15, No. 3:367-91.

Romer, P. L., 1986, “Increasing Returns and Long-Run Growth?” , Journal of Political Economy 94 (October): 1002-1037.

Sacerdoti, E., S. Brunschwig, and J. Tang, 1998, “The impact of human capital on growth : evidence from West Africa", IMF working paper ; WP/98/162

Svensson J., 1999 “Aid, Growth and Democracy” Economics and Politics, Vol. 11, pp 275297. 


\section{Main Elements of A NeOClassical TyPe Growth Model}

Following Favero (2001) we analyze the main features of the neoclassical growth models starting with a Cobb-Douglas production function where output, Y, is determined according to: $Y_{t}=K_{t}^{\alpha} \times\left(A_{t} \times L_{t}\right)^{1-\alpha}$, with $0<\alpha<1 . L$, labor, and $K$, physical capital are the two inputs that are remunerated at their marginal productivities. The capital stock series follows the perpetual inventory accumulation framework, and saving is supposed to be identical to investment: $K_{t} \equiv K_{t-1} \times(1-\delta)+I_{t}$ and $S_{t} \equiv I_{t}$. The model also assumes a constant marginal propensity to save, $s=S / Y$. Technology, $A$, and labor, $L$, grow at a constant rate, respectively, $g$ and $n: L_{t}=L_{t-1} \times(1+n)$, and $A_{t}=A_{t-1} \times(1+g)$, where subscripts $t$ stands for the time period and $t$ describes the time period.

The per capita steady-state output growth, $y^{*}$, is hence derived as:

$$
\ln y^{*}=\ln A+g \times t+\frac{\alpha}{1-\alpha} \ln s-\frac{\alpha}{1-\alpha} \ln (n+g+\delta)
$$

The per capita output growth fluctuates randomly around its steady-state level. Furthermore, the model supposes that $\ln A$ represents not only the level of technology but also other country-specific factors that can eventually impact domestic growth such as institutions, political and social stability, market structure, environment, and policy variables. These two assumptions introduce a stochastic structure into the deterministic representation of the per capita steady state output growth of equation (A1.1). This gives Solow's simple representation of per capita output path that forms the basis of the core part of the empirical literature conducted on growth determinants and growth accounting:

$$
\ln y_{i}=a+g \times t+\frac{\alpha}{1-\alpha} \ln s_{i}-\frac{\alpha}{1-\alpha} \ln \left(n_{i}+g+\delta\right)+\varepsilon_{i}
$$

where $\ln A=a+v_{i} ; \ln y_{i}=\ln y^{*}{ }_{i}+u_{i}$, and $\varepsilon_{i}=u_{i}+v_{i} . v_{i}$ is a country-specific shock and $u_{i}$ an independent and identically distributed (i.i.d.) disturbance that randomly induces deviations for a short-term period, of the level of realized per capita output from its steadystate level.

The basic Solow model has been used extensively to estimate the determinants of growth and the shares paid to capital inputs. The derived point estimates obtained might contain a bias due to a possible under-parameterization of the model. Mankiw, Romer and Weil (1992) address this misspecification by introducing human capital as an explanatory variable in the context of a model known as Human Capital Augmented (HCA) Solow Model. The HCASolow model considers the production function $Y_{t}=K_{t}{ }^{\alpha} \times H_{t}{ }^{\beta} \times\left(A_{t} \times L_{t}\right)^{1-\alpha-\beta}$ and describes the path of per capita output as follows:

$$
\ln y_{i}=a^{\prime}+g \times t+\frac{\alpha}{1-\alpha-\beta} \ln s_{k i}+\frac{\beta}{1-\alpha-\beta} \ln s_{h i}-\frac{\alpha+\beta}{1-\alpha-\beta} \ln \left(n_{i}+g+\delta\right)+\varepsilon^{\prime}{ }_{i}
$$

where $s_{k}$ and $s_{h}$ represent the shares of output invested in physical and human capital respectively, and subscript i a country. 
The HCA Solow model can be rewritten for an explicit treatment of country-specific variables that capture some of the unexplained patterns of growth dynamics and differences in steady-state level of income per capita across WAEMU countries. Assuming that the error term $\varepsilon_{i}^{\prime}$ is correlated with policy or structural variables, $X_{i}$, we can express it as:

$\varepsilon_{i}^{\prime}=\varepsilon_{0}+\gamma^{\prime} \times X_{i}+\eta_{i}$. Hence, the model is as follows:

$\ln y_{i}=\gamma_{0}+g \times t+\frac{\alpha}{1-\alpha-\beta} \ln s_{k i}+\frac{\beta}{1-\alpha-\beta} \ln s_{h i}-\frac{\alpha+\beta}{1-\alpha-\beta} \ln \left(n_{i}+g+\delta\right)+\gamma^{\prime} \times X_{i}+\eta_{i}(\mathrm{~A} 1.4)$

The nonstochastic part of the right hand side of (1.4) is the path of the steady state-level of per capita income, controlling for country specific effects. This might overcome the omitted variable bias of equation (A1.3). Furthermore, when the misspecification yielded an upward bias of the point estimates of $\alpha$ and $\beta$, the right specification of the model might give estimates that are consistent with the convergence hypothesis. 


\section{ESTIMATION ISSUES, AND INCONSISTENCY DUE TO IGNORED HETEROGENEITY}

Several methods have been proposed in the literature to estimate panel data models. The first studies on convergence (e.g., Barro, 1991) estimated models of growth with panel data using prior beliefs on homogeneity among countries as suggested by the Solow model. The recent debates in the econometric literature focus on the right way to account for country heterogeneity. Formally, country heterogeneity can be detected in the regression equation at the level of the intercepts or in the slope parameters. Fixed effects and random effects estimators take into account country heterogeneity in the constant term, based on different assumptions and set of constraints on the generating process of the intercept. Although the choice "fixed effects versus random effects" can be dealt with quite simply by the implementation of the Hausman test, this test does not address the issue of slope heterogeneity. Several studies have used the fixed effects model to estimate the speed of convergence. Recent contributions in the econometric literature on panel data, however, show that those estimators are heavily biased and inconsistent. Lee, Pesaran, and Smith (1998) argue that the estimator of the speed of convergence obtained by Barro in his celebrated 1991 paper is inconsistent since it incorrectly assumes homogeneity of growth rates across countries. They further argue that the right way to account for heterogeneity is to consider an unrestricted model that allows for country differences in steady-state levels or rates of growth, and different convergence speeds across countries. The reasons for the inconsistency in speed of adjustment estimates that are based on mistaken homogeneity assumptions are presented below.

Consider the following autoregressive with distributed lag $\operatorname{ARDL}(1,0)$ model that encompasses the representation of growth dynamics as given by equation (1.3):

$$
y_{i t}=\alpha_{i}+\lambda_{i} \times y_{i t-1}+\beta_{i} \times x_{i t}+\varepsilon_{i t}
$$

For the sake of simplicity we consider $x_{i t}$ to be a scalar random variable. Results obtained in this setting are valid in the context of equation (1.3) with country-specific slopes and intercepts, where $x_{i t}$ represents a vector of variable, comprising the Solow determinants of growth and other policy variables. Equation (A2.1) can be rewritten as:

$$
\Delta y_{i t}=\alpha_{i}-\left(1-\lambda_{i}\right) \times\left(y_{i t-1}-\theta_{i} \times x_{i t}\right)+\varepsilon_{i t},
$$

or

$$
\Delta y_{i t}=\alpha_{i}-\phi_{i} \times\left(y_{i t-1}-\theta_{i} \times x_{i t}\right)+\varepsilon_{i t}
$$

where $\theta_{i}=\frac{\beta_{i}}{\left(1-\lambda_{i}\right)}$ represents the long run coefficient of $x_{i t}$ for the i-th group.

Let us consider that the slope heterogeneity is taken into account according to the following random coefficients model:

$$
\phi_{i}=\phi+\eta_{i 1}
$$




$$
\theta_{i}=\theta+\eta_{i 2}
$$

that yields:

$$
\beta_{i}=\theta_{i} \times \phi_{i}=\theta \times \phi+\eta_{i 3}
$$

where

$$
\begin{gathered}
\eta_{i 3}=\phi \times \eta_{i 2}+\theta \times \eta_{i 1}+\eta_{i 1} \times \eta_{i 2} \\
\left(\begin{array}{l}
\eta_{i 1} \\
\eta_{i 2}
\end{array}\right) \sim \operatorname{iid}\left[\left(\begin{array}{l}
0 \\
0
\end{array}\right),\left(\begin{array}{cc}
\omega_{11} & \omega_{12} \\
\omega_{12} & \omega_{22}
\end{array}\right)\right], \text { and } \omega_{33}=V\left(\eta_{i 3}\right)=V\left(\phi \times \eta_{i 2}+\theta \times \eta_{i 1}+\eta_{i 1} \times \eta_{i 2}\right)
\end{gathered}
$$

Letting $\lambda=1-\phi$ and $\beta=\theta \times \phi$, equation (A.1) can be rewritten as follows:

$$
\begin{aligned}
& y_{i t}=\alpha_{i}+\lambda \times y_{i t-1}+\beta \times x_{i t}+v_{i t} \\
& v_{i t}=\varepsilon_{i t}-\eta_{i 1} \times y_{i t-1}+\eta_{i 3} \times x_{i t}
\end{aligned}
$$

Equation (A2.9) shows clearly that the residual term in the regression is correlated with the regressors, yielding inconsistent fixed or random estimators. Moreover, the inconsistency of the estimators cannot be eliminated asymptotically. Hence, incorrectly ignoring heterogeneity in a dynamic panel data model have yielded inconsistent estimators of the speed of adjustment that will tend to zero even if the source of heterogeneity is random. Studies that have this weakness have yield downward-biased estimators, as shown by Lee, Pesaran, and Smith (1997 and 1998) theoretically and also empirically, using Summer and Heston panel data.

To address this inconsistency, alternative estimators have been proposed, including the mean group estimator (MGE) and the pooled mean group estimator (PMGE). The MGE of dynamic heterogeneous panels is produced by a two step procedure. In the first step the country specific parameters are estimated, using Ordinary Least Squares (OLS). Then the MGE estimators are obtained by averaging (nonweighted average) these estimators across countries. However, when the time horizon is small, the MGE estimator is biased and can yield misleading results, although Hsiao, Pesaran, and Tahmiscioglu (1999) and Pesaran and Zhao (1999) propose alternative methods to address this small sample bias. If the Solow model's homogeneity assumption holds, the appropriate estimator to be used is the pooled fixed effects estimate or the PMGE that is obtained through maximizing the quasi-maximum likelihood of the dependent variable in equation (A2.3). The Solow assumption can be tested using a likelihood ratio test or a Hausman type test of parameter homogeneity which compares the MGE and the PMGE directly. Consistent estimates of the mean of the long-run coefficients can be easily obtained from the MGE. These, however, will be inefficient if slope homogeneity holds. Under slope homogeneity, the PMGE is consistent and efficient. Therefore, the effects of heterogeneity on the means of the parameters can be determined by a Hausman-type test between the MGE and fixed effects, or PMGE. 


\section{Testing the Presence of Unit Root in Panel Data}

Consider the stochastic process, $x_{i t}$, generated by the first order autoregressive process:

$$
x_{i t}=\left(1-\phi_{i}\right) \times \mu_{i}+\phi_{i} \times x_{i t-1}+\varepsilon_{i t}
$$

There is a unit root in $x_{i t}$ if the coefficient on its lagged value is equal to one. Rewrite equation (A3.1) as follows:

$$
\Delta x_{i t}=\alpha i \times \mu_{i}+\beta_{i} \times x_{i t-1}+\varepsilon_{i t}
$$

where $\alpha_{i}=\left(1-\phi_{i}\right) \times \mu_{i}$ and $\beta_{i}=-\left(1-\phi_{i}\right)$.

The null hypothesis of unit root can be expressed as:

$$
H_{0}: \quad \beta_{i}=0 \text { for all } \mathrm{i},
$$

against the alternative

$$
\begin{array}{ll}
H 1: & \beta_{i}<0, \quad i=1,2 \ldots ., N_{1} \\
& \beta_{i}=0, \quad i=N_{1}+1, N_{1}+2, \ldots . . N
\end{array}
$$

This formulation of the alternative hypothesis allows for some of the individual countries to have a unit root and is more general than the homogenous alternative hypothesis. I use the panel unit root tests proposed recently by Im, Pesaran, and Shin (IPS, 2002), and that distinguishes two cases corresponding to the Dickey Fuller (DF) and the Augmented Dickey Fuller tests for univariate time series. The simplest case for this test is when the errors are not serially correlated. In this context, the IPS unit root test is based on the standardized t-bar statistic given as:

$$
\Gamma_{\bar{t}}=\frac{\sqrt{N} \times\left[\bar{t}_{N T}-E\left(\eta_{T}\right)\right]}{\sqrt{\operatorname{Var}\left(\eta_{T}\right)}}
$$

where $\bar{t}_{N T}$ is obtained by averaging across countries the DF statistic for the country by country unit root test, and with $E\left(\eta_{T}\right)$ and $\operatorname{Var}\left(\eta_{T}\right)$ representing respectively the mean and the variance of $\eta_{i T}$ defined by $\eta_{i T}=\frac{\sqrt{T-2} \times\left(\varepsilon_{i}^{\prime} \times M_{\tau} \times s_{i,-1}\right)}{\sqrt{\left(s_{i,-1}^{\prime} \times M_{\tau} \times s_{i,-1}\right) \times\left(\varepsilon_{i}^{\prime} \times M_{\tau} \times \varepsilon_{i}\right)}}$, in which equation $M \tau=I_{T}-\tau_{T} \times\left(\tau_{T}^{\prime} \times \tau_{T}\right)^{-1} \times \tau_{T}^{\prime}, \tau_{T}=(1,1, \ldots \ldots \ldots, 1)^{\prime} ; \quad s_{i,-1}=\left(s_{i 0}, s_{i 1}, \ldots . . s_{i T-1}\right)^{\prime} ; \quad s_{i t}=\sum_{j=1}^{t} \varepsilon_{i j}$

If the errors are serially correlated, the test statistic is transformed to account for this serial correlation in the averaging formula for $\bar{t}_{N T}$ and in using a modified standardized t-bar statistic. The IPS unit root test assumes that the errors are generated independently across countries and is no longer applicable if this assumption does not hold. In this case, we need to remove the effect of the common time-specific component of the autoregressive representation of the stochastic process, and apply the standardized t-bar testing procedure to the demeaned regressions to test the null hypothesis of unit root. 
Table A3.1. Panel Unit Root Tests for Solow Growth Variables

\begin{tabular}{|c|c|c|c|c|c|c|}
\hline \multirow{3}{*}{ Real GDP per capita } & \multicolumn{2}{|c|}{ Raw data } & \multicolumn{2}{|c|}{ Demeaned data } & \multirow{2}{*}{$\begin{array}{l}\text { Unit } \\
\text { root }\end{array}$} & \multirow{2}{*}{$\begin{array}{l}\text { Level of } \\
\text { Integration }\end{array}$} \\
\hline & $\mathrm{ADF}(1)$ & $\operatorname{ADF}(2)$ & $\mathrm{ADF}(1)$ & $\mathrm{ADF}(2)$ & & \\
\hline & & & & & Yes & $\mathbf{I}(\mathbf{1})$ \\
\hline $\bar{t}_{N T}$ & -1.2 & -1.0 & -1.4 & -1.0 & & \\
\hline$\sqrt{\operatorname{Var}\left(\bar{t}_{N T}\right)}$ & 0.8 & 1.1 & 0.5 & 0.7 & & \\
\hline Real GDP per capita & & & & & & \\
\hline Growth & & & & & No & $\mathbf{I}(\mathbf{0})$ \\
\hline $\bar{t}_{N T}$ & -4.5 & -3.4 & -4.5 & -3.5 & & \\
\hline$\sqrt{\operatorname{Var}\left(\bar{t}_{N T}\right)}$ & 1.1 & 0.6 & 1.1 & 0.9 & & \\
\hline Investment share & & & & & No & $\mathbf{I}(\mathbf{0})$ \\
\hline $\bar{t}_{N T}$ & -2.1 & -2.2 & -2.2 & -2.2 & & \\
\hline$\sqrt{\operatorname{Var}\left(\bar{t}_{N T}\right)}$ & 0.7 & 0.6 & 0.6 & 0.5 & & \\
\hline Labor force growth & & & & & No & $\mathbf{I}(\mathbf{0})$ \\
\hline $\bar{t}_{N T}$ & -2.0 & -2.0 & -2.4 & -2.6 & & \\
\hline$\sqrt{\operatorname{Var}\left(\bar{t}_{N T}\right)}$ & 0.4 & 0.6 & 0.5 & 0.6 & & \\
\hline Human capital growth & & & & & No & $\mathbf{I}(\mathbf{0})$ \\
\hline $\bar{t}_{N T}$ & -1.5 & -1.4 & -1.7 & -1.7 & & \\
\hline$\sqrt{\operatorname{Var}\left(\bar{t}_{N T}\right)}$ & 0.9 & 0.8 & 0.7 & 0.9 & & \\
\hline
\end{tabular}




\section{SENSIBILITy OF RESUlts To ECONOMETRIC METHOdOLOGY}

Table A4.1. Static Fixed Effects Estimates of the Augmented Solow Model

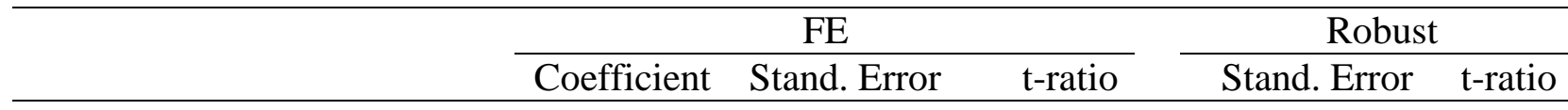

Dependent variable: Log of GDP per capita

Log of investment share

Log of labor force growth

Log of human capital growth

Time trend
0.1549

0.3817

0.2521

0.0017

$\begin{array}{rr}0.0249 & 6.2148 \\ 0.172 & 2.219 \\ 0.0891 & 2.8289 \\ 0.0007 & 2.3765\end{array}$

$0.0919 \quad 1.6864$

$0.3201 \quad 1.1923$

$0.09 \quad 2.8023$

$0.0012 \quad 1.4019$

The estimation of the static Solow model using fixed-effects technology gives quite intuitive results. The impacts of investment in physical and human capital are positive and significant. However, the positive and significant coefficient on labor force growth is not consistent with the prediction of the Solow model. In using robust methods for the estimation, the labor force growth is now found to be insignificant but the impact of human capital is still positive and significant. Results based on this category of estimation methodologies have been frequently presented in the literature in the early development of panel data estimation methods, although they are misleading since the variables might be cointegrated (see tests of unit root above), yielding a spurious correlation.

Table A4.2. Dynamic Fixed Effects Estimates of the Augmented Solow Model

\begin{tabular}{llllll}
\hline & \multicolumn{2}{c}{ FE } & & \multicolumn{2}{c}{ Robust } \\
\cline { 2 - 3 } \cline { 5 - 6 } & Coefficient & Std. Error & t-ratio & & Std. Error t-ratio \\
\hline
\end{tabular}

Dependent variable: Log of GDP per capita

Long-run coefficients

Log of investment share

0.3397

0.1048

3.241

0.0966

3.5153

Log of labor force growth

1.3447

$\begin{array}{ll}0.683 & 1.9687\end{array}$

$0.7464 \quad 1.8015$

Log of human capital growth

0.2209

$0.3243 \quad 0.6812$

$0.2482 \quad 0.8898$

Error correction coefficients

Phi

$-0.1166$

$0.0293-3.978$

$0.0222 \quad-5.265$

Short-run coefficients

Log of investment share

0.0396

$\begin{array}{ll}0.0112 & 3.523\end{array}$

$\begin{array}{ll}0.0114 & 3.4752\end{array}$

Log of labor force growth

0.1568

0.0734

2.1381

$\begin{array}{ll}0.0624 & 2.5128\end{array}$

Log of human capital growth

0.0258

0.0385

0.6684

$0.0323 \quad 0.7965$

Time trend

0.0003

$0.0003 \quad 1.0877$

$0.0002 \quad 1.543$ 
The introduction of dynamics in the specification of the model improves the results and dramatically reduces their sensitivity to the estimation technique used. The fixed effects estimation and its robust version give broadly the same results. Human capital is no longer significant and the long-term statistical significance of labor force growth is barely supported by these models, although the coefficient sign is still positive and its impact shows up strongly in the short run. The dynamic fixed effect regression technique has been the most widely used approach these past years in attempts to estimate growth and convergence with panel data. The results generally presented in the literature are also consistent with those presented in Table 2 which show an important positive impact of investment and saving on growth but no role for human capital in explaining the steady-state path of growth and differences in countries' GDP per capita.

Table A4.3. Summary of Results of OLS and PMLE Versions of the Long-run Coefficients Based on ARDL Specifications with Pre-Specified Lags

\begin{tabular}{|c|c|c|c|c|c|c|c|c|}
\hline \multirow[b]{2}{*}{ Country } & \multicolumn{4}{|c|}{ OLS VERSION } & \multicolumn{4}{|c|}{ PMLE VERSION } \\
\hline & Phi & liy & llfg & lqp & Phi & liy & llfg & lqp \\
\hline \multicolumn{9}{|c|}{ Dependent variable: lyca } \\
\hline \multirow[t]{2}{*}{ BENIN } & -0.244 & 0.335 & -0.665 & -6.5 & -0.196 & 0.167 & 0.079 & 0.386 \\
\hline & -1.95 & 1.26 & -0.48 & -1.41 & -2.04 & 3.71 & 0.45 & 2.82 \\
\hline \multirow[t]{2}{*}{ BURKINA FASO } & -0.14 & 0.438 & 0.358 & -2.124 & -0.027 & 0.167 & 0.079 & 0.386 \\
\hline & -1.92 & 4.52 & 0.16 & -0.81 & -0.64 & 3.71 & 0.45 & 2.82 \\
\hline \multirow[t]{2}{*}{ COTE D'IVOIRE } & -0.106 & 0.768 & 1.18 & 7.212 & -0.145 & 0.167 & 0.079 & 0.386 \\
\hline & -1.34 & 1.22 & 0.77 & 1.03 & -1.75 & 3.71 & 0.45 & 2.82 \\
\hline \multirow[t]{2}{*}{ MALI } & -0.66 & -0.101 & 0.684 & -0.012 & -0.13 & 0.167 & 0.079 & 0.386 \\
\hline & -3.19 & -2.35 & 1.07 & -0.15 & -1.48 & 3.71 & 0.45 & 2.82 \\
\hline \multirow[t]{2}{*}{ NIGER } & -0.5 & 0.218 & 0.029 & 7.046 & -0.141 & 0.167 & 0.079 & 0.386 \\
\hline & -2.44 & 2.91 & 0.03 & 5.60 & -2.20 & 3.71 & 0.45 & 2.82 \\
\hline \multirow[t]{2}{*}{ SENEGAL } & -0.553 & 0.216 & 0.484 & -0.476 & -0.517 & 0.167 & 0.079 & 0.386 \\
\hline & -3.39 & 2.92 & 0.95 & -0.26 & -3.92 & 3.71 & 0.45 & 2.82 \\
\hline \multirow[t]{2}{*}{ TOGO } & -0.802 & 0.088 & -0.06 & 0.487 & -0.708 & 0.167 & 0.079 & 0.386 \\
\hline & -3.86 & 1.42 & -0.34 & 3.34 & -3.75 & 3.71 & 0.45 & 2.82 \\
\hline
\end{tabular}

Figures in italics are t-statistics liy, llfg, and lqp represent respectively the log of investment share, the log of labor force growth, and the log of human capital growth. Phi, the coefficient of the error correction model, measures the speed of convergence. 
To address the drawbacks of the models presented above, we consider the following

$$
\begin{aligned}
& \text { ARDL }(p, \underbrace{q, \underline{q, q \ldots ., q} q}_{k \text {-times }}) \text { model } \\
& y_{i t}=\sum_{j=1}^{p} \lambda_{i j} \times y_{i, t-j}+\sum_{j=0}^{q} \delta^{\prime}{ }_{i j} \times x_{i t-j}+\varepsilon_{i t}
\end{aligned}
$$

in which fixed regressors (constant and time trend) are introduced without loss of generality. This model can be re-parameterized in the following error correction model by subtracting the lagged dependent variable (GDP per capita) from both sides.

$$
\Delta y_{i t}=\phi_{i} \times y_{i t-1}+\beta^{\prime} \times x_{i t}+\sum_{j=1}^{p-1} \lambda *_{i j} \times \Delta y_{i, t-j}+\sum_{j=0}^{q-1} \delta^{* \prime}{ }_{i j} \times \Delta x_{i t-j}+\varepsilon_{i t}
$$

Following Pesaran, Shin, and Smith (1999), we assume that the $\operatorname{ARDL}(p, q, q, \ldots . ., q)$ is stable in the sense that the roots of $1-\sum_{j=1}^{p} \lambda_{i j} \times z^{j}=0$ fall outside the unit circle for all $i$. This assumption ensures that $\phi_{i}<0$ and that there is a long run relationship between per capita output, and the investment in physical and human capital defined by $y_{i t}=-\left(\frac{\beta_{i}}{\phi_{i}} \times x_{i t}+\eta_{i t}\right)$, where $\eta_{i t}$ is $\mathrm{I}(0)$. Although country specific changes of real economic activity should be allowed in the short run as a response to changes in investment in human and physical capital, we assume that, given the similar structure of the economies, the long run impact of those variables are the same. Hence, the long-run coefficients on $x_{i}$, defined by $\theta_{i}=-\frac{\beta_{i}}{\phi_{i}}$ are supposed to be the same across the seven WAEMU countries. It may be of interest, in further research on growth in the zone, to constrain only a subset of the long-run parameters to be the same across countries to identify the variables for which such an hypothesis is statistically sustainable and to investigate the socioeconomic reasons. Tests of the homogeneity of error variances and/or the equality of (some of) the short- or long-run slope coefficients across countries can be readily carried out using the Likelihood Ratio or other classical statistical procedure, since the PMG and fixed effects estimators are obtained using restricted versions of the set of individual country equations. We present an alternative testing procedure à la Hausman. Under the long-run slope homogeneity hypothesis the Hausman statistic is asymptotically distributed as a $\chi 2$ with three degrees of freedom.

Assuming that all long run coefficients are the same across WAEMU countries, the error correction model for the estimation of the partial adjustment $A R D L(1,0,0,0)$ model can be written in the following compact form: $\Delta y_{i}=\phi_{i} \times \xi_{i}(\theta)+\varepsilon_{i}$, where $\xi_{i}(\theta)=y_{i-1}-a_{0}-g \times t-\alpha_{2} \times x_{2 i}-\alpha_{2} \times x_{2 i}-\alpha_{3} \times x_{3 i}$ represents the error correction 
component. It should be noted that (i) the regression equations for each country are nonlinear in $\phi_{i}$ and $\theta$, (ii) the long-run homogeneity assumption introduces restrictions on the cross equation parameters, and (iii) the error variances differ across countries. The estimates of the long-run coefficients, $\theta$, and the group-specific error-corrections coefficients, $\phi_{i}$, are the quasi-maximum likelihood estimators that have been averaged across countries to obtain group-wide mean estimates of the error correction coefficients and the other short-run parameters of the model. 